\title{
A Case of Huge Vocal Polyp in a Patient With Difficult Laryngeal Exposure Treated by Fiberoptic Laryngeal Laser Surgery Under Local Anesthesia
}

\author{
You Young An (D), Jeong Hyun Lee (D), Ki Nam Park (D), and Seung Won Lee (iD) \\ Department of Otolaryngology-Head and Neck Surgery, Soonchunhyang University Bucheon Hospital, \\ Soonchunhyang University College of Medicine, Bucheon, Korea \\ 전신마취 하 후두미세수술이 불가능한 경추 손상 환자에게서 \\ 국소마취 하 굴곡내시경 후두 레이저 수술로 치료한 거대한 성대 폴립 1예
}

안유영, 이정현, 박기남, 이승원

순천향대학교 의과대학 부천병원 이비인후-두경부외과학교실

Indications of fiberoptic laryngeal laser surgery (FLS) procedure have broadened by the development of flexible fiberoptic endoscopes and flexible laser systems. FLS procedure performed under local anesthesia and it is the unique value of FLS. The surgery can be performed on patients who are impossible to undergo general anesthesia and difficult to be exposed by laryngeal microsurgery. Main indication of FLS procedure was small to moderate sized hemorrhagic vocal polyp, but we experienced a case of huge vocal polyp with difficult laryngeal exposure treated by FLS procedure under local anesthesia. The vocal polyp was removed successfully without vocal fold scar through fiberoptic laryngeal laser surgery under local anesthesia.

Keywords Larynx; Exposure; Polyps; Vocal cords; Fiberoptic laryngeal laser surgery.

\section{서 론}

굴곡내시경과 레이저의 발달로 성대질환에서 적용할 수 있는 굴곡내시경 후두 레이 저 수술(fiberoptic laryngeal laser surgery [FLS] under local anesthesia)의 적응증이 넓어졌다[1]. 굴곡내시경 후두 레이저 수술은 국소마취 하에 시행하며, 이는 전신마취가 불가능한 전신상태의 환자도 수술이 가능하고 마취 관련 합병증이 없으며, 후두경을 이 용하여 수술 시야를 확보하는데 제한이 있는 difficult laryngeal exposure (DLE) 환자 에서 수술을 시행할 수 있다는 장점이 있다. 이는 기존의 후두미세수술(laryngeal microsurgery)이 불가능한 환자에서 또 하나의 치료(treatment modality)로서 고유가치 (unique value)를 가진다[2]. 반면에 구역 반사(gag reflex)가 심하거나 불안하고 예민한 환자의 경우 수술을 종결할 수 없을 가능성이 증가하며, 크기가 작거나 중간 크기의 양 성 병변(small to moderate sized benign vocal fold lesion)에 좀더 적합한 술식으로 알
Received August 23, 2021

Revised October 5, 2021

Accepted December 9, 2021

\section{Corresponding Author}

Seung Won Lee, MD, PhD Department of OtolaryngologyHead and Neck Surgery, Soonchunhyang University Bucheon Hospital, Soonchunhyang University College of Medicine,

170 Jomaru-ro, Bucheon 14584, Korea

Tel +82-32-621-5448

$\mathrm{Fax}+82-32-621-5016$

E-mail Isw0922@schmc.ac.kr

\section{ORCID iDs}

You Young An (D)

https://orcid.org/0000-0001-6695-7655 Jeong Hyun Lee (D) https://orcid.org/0000-0003-1641-5924 Ki Nam Park (D) https://orcid.org/0000-0001-6641-3981 Seung Won Lee (iD

https://orcid.org/0000-0002-0468-8143

\footnotetext{
This is an Open Access article distributed under the terms of the Creative Commons Attribution Non-Commercial License (https://creativecommons.org/ licenses/by-nc/4.0) which permits unrestricted non-commercial use, distribution, and reproduction in any medium, provided the original work is properly cited.
} 

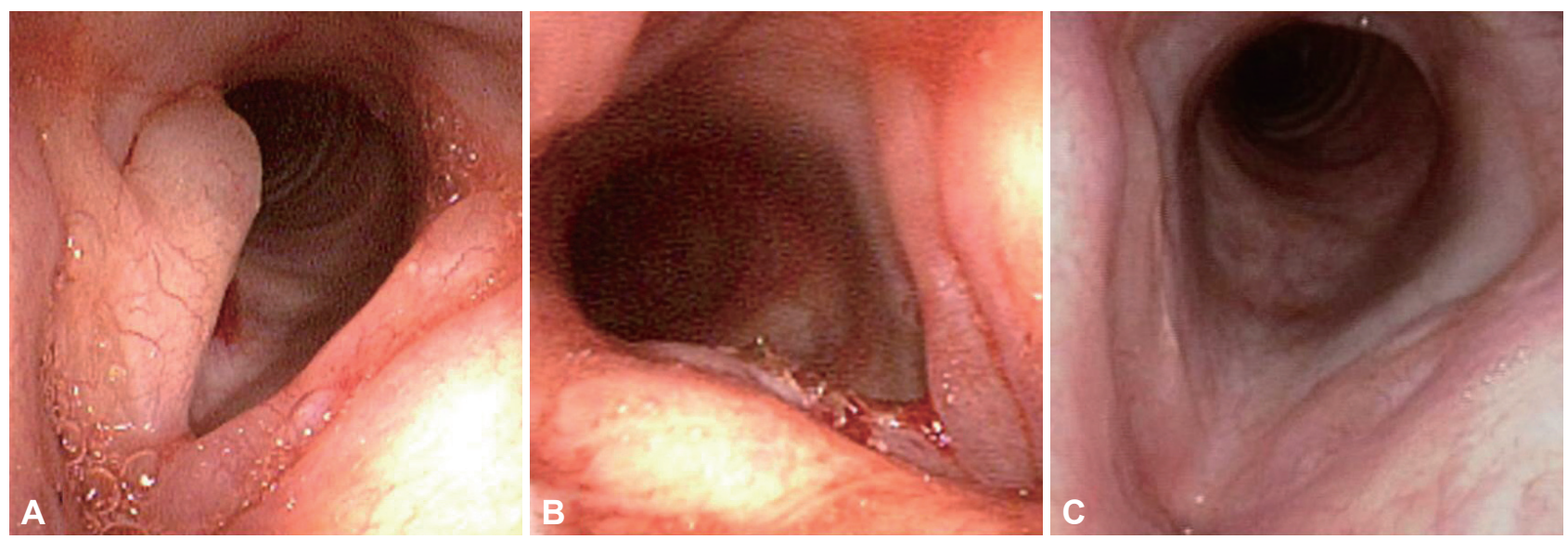

Fig. 1. Fiberoptic findings of huge vocal polyp. (A) is a pedunculated huge polyp hanging at the right side of vocal fold (VF). (B) is an immediate finding after fiberoptic laryngeal laser surgery at the operating room. (C) is a postoperative image which shows no VF scar after 3 months.

려져 있다[3].

저자는 시야확보가 어렵고 전신마취가 불가능한 DLE 환 자의 거대 성대 폴립을 국소마취 하 굴곡내시경 후두 레이저 수술을 이용하여 성대에 반흔을 유발하지 않고 성공적으로 절제하였다. 이는 굴곡내시경 후두 레이저 수술로 치료한 특 수한 증례이기에 문헌고찰과 함께 보고하는 바이다.

\section{증 례}

20년 전 낙상으로 인한 경추 외상력이 있는 60세 남성이 2년 간 지속된 목소리 변화를 주소로 타 병원 외래에 내원하여 시 행한 이학적 검사상, 우측 성대에 호흡에 따라 펄럭이는 거대 한 폴립이 확인되었다(Fig. 1A). 해당 병원에서 전신마취 하 후두미세수술을 시도하였으나, 경추 외상력으로 인한 경부 신 전 장애로 기관 삽관이 불가능하였고, 후두미세수술을 시행 할 수 없어 본원으로 의뢰되었다(Fig. 2).

국소마취 하 굴곡내시경 후두 레이저 수술을 시행하기 위 해 술 전 midazolam 0.03-0.05 mg/kg을 정맥 주사하여 환 자를 진정시키고, 1:100000 epinephrine, 1\%-2\% lidocaine 용액을 적신 거즈로 코 패킹을 하였다. 이후 굴곡 후두 내시경 의 working channel을 이용하여 spray catheter를 통해 4\% lidocaine을 후두 부위에 분사하여 후두 부위를 국소마취하 였다. 이후 굴곡 후두 내시경을 이용하여 거대 성대 폴립을 확 인하였고, 내시경의 working channel을 통해 $532 \mathrm{~nm}$-pulsed potassium-titanyl-phosphate (KTP) 레이저(QUANTA D532-6; Quanta System S.p.A., Varese, Italy)를 진입시켜 거대한 폴립 의 성대 부착 부위에 레이저 끝부분을 위치시켰다. KTP 레이 저를 $8 \mathrm{Watt}, 2 \mathrm{~Hz}$ 로 설정하였으며, 총 $600 \mathrm{~J}$ 의 레이저를 조사 후 절제된 부위를 바이옵시 포셉(biopsy forceps)을 이용하여

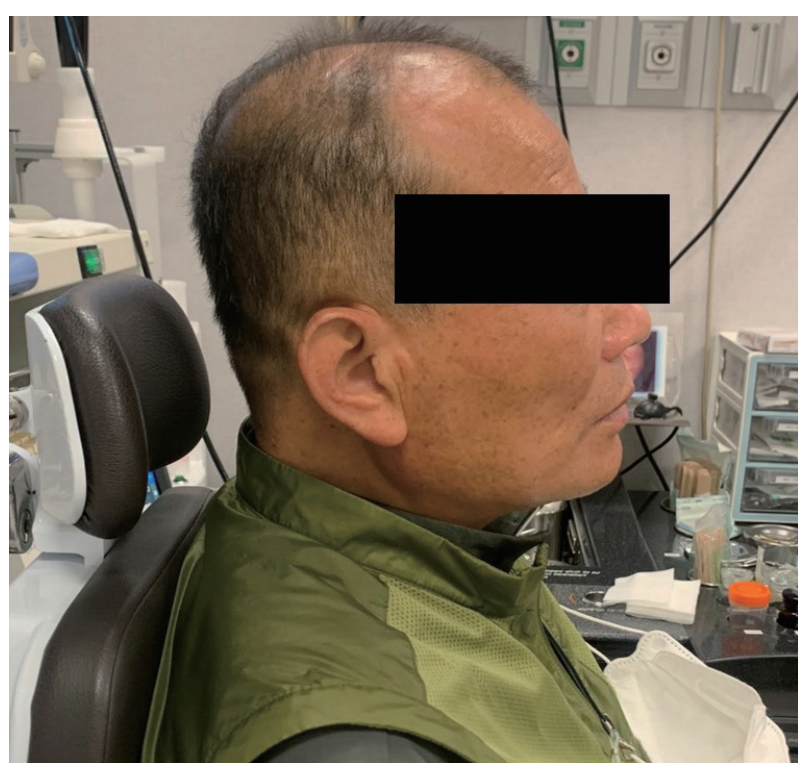

Fig. 2. Lateral view of the patient with difficult laryngeal exposure. The informed consent was obtained from the patient.

제거하였다(Fig. 1B). 이후 수술 부위 반흔을 예방하기 위해 경 갑상설골막 접근법(transthyrohyoid membrane approach)으 로 우측 성대 내에 스테로이드(tamceton)를 주입 후 수술을 마쳤다. 해부학적 검사를 통해 $1.0 \times 0.6 \times 0.3 \mathrm{~cm}$ 크기의 성대 폴립으로 최종 진단되었으며, 환자는 수술 후 출혈이나 호흡 곤란 등 합병증 없이 퇴원하였다.

수술 후 3 개월 이후 외래 추적 관찰 상 후두내시경 소견에서 수술부위에 반흔없이 회복중인 모습을 보였으며(Fig. 1C), 주관적으로 애성이 호전되었다고 보고하였다. 수술 후 1개월 및 3개월 이후에 시행한 음성 분석 검사 및 후두 스트로보스 코피 검사에서 주관적인 음성평가 지표인 voice handicap index (VHI), mucosal wave, glottal closure 모두 호전을 보였 
Table 1. Preoperative and postoperative voice parameters

$\begin{array}{lccccccc} & \text { MPT (sec) } & \text { Jitter (\%) } & \text { Shimmer (\%) } & \text { HNR (dB) } & \text { VHI } & \text { Mucosal wave } & \text { Glottal closure } \\ \text { Baseline } & 10.89 & 1.83 & 6.72 & 10.83 & 28 & 1 & 1 \\ \text { Post-operative 1 month } & 10.90 & 0.44 & 2.61 & 17.67 & 14 & 2 & 3 \\ \text { Post-operative 3 months } & 12.71 & 0.18 & 1.33 & 27.45 & 0 & 2 & 3\end{array}$

All subjective and objective voice parameters are significantly improved at postoperative 1 month and 3 months. Mucosal wave: $0=$ absent, $1=$ severely reduced, $2=$ mildly reduced, and $3=$ intact. Glottal closure: $0=$ severe, $1=$ moderate, $2=$ mild, and $3=$ absent. MPT, maximum phonation time; HNR, hamonics to noise ratio; VHI, voice handicap index

으며, 객관적인 지표인 최대발성시간(maximum phonation time), 주파수변동률(jitter), 진폭변동률(shimmer), 배음 대 잡음비(harmonics to noise ratio) 역시 모두 호전을 보였다 (Table 1). 수술에 대한 만족도(procedure satisfaction, 0-10) 또한 10점으로 높게 유지되는 상태로 추가적인 문제없이 외래 에서 추적 관찰중에 있다.

\section{고 찰}

국소마취 하 굴곡내시경 후두 레이저 수술은 전신마취를 피할 수 있고, 수술 시간이 짧고 기술적으로 어렵지 않다는 점에서 후두미세수술을 대체할 수 있는 대체가치(alternative value)를 가진다[2,4]. 또한, 후두미세수술은 수술 시 전신마 취 하 후두경을 사용하여 시야를 확보하게 되는데, 환자의 전 신상태가 전신마취가 불가능하거나 여러 원인으로 인하여 수 술 시야가 확보되지 않는 경우가 있다. 전신 비만한 경우(body mass index $>25$ ), 목이 굵고 짧은 경우, 입을 벌리기 힘든 경우, 하악후퇴증이 있거나 하악이 작은 경우, 대설증이 있는 경우, 경추 이상으로 경부 신전이 안되는 경우 등이 그러하다[5]. 굴곡 내시경 후두 레이저 수술은 이러한 후두미세수술이 불가능한 DLE 환자 또는 전신마취가 불가능한 전신상태의 환자에서 국 소마취로 수술이 가능하다는 점에서 고유가치를 가진다[2].

본 증례에서 환자는 경추 외상력으로 인한 경부 신전 장애 로, 후두경으로 시야를 확보할 수 없으며, 기관 삽관 실패로 인해 전신마취 하 수술이 불가능하였다. 굴곡내시경 후두 레 이저 수술은 국소마취 하에서 수술하기 때문에 거대 폴립의 경우 환자가 힘들어 하는 경우가 많아 일반적으로 시행하지 않으나, 본 증례의 경우 후두미세수술이 불가능하고 환자는 목소리 증상으로 삶에 지장이 있어 수술적 치료를 원했다. 이 에 저자는 국소마취 하 굴곡내시경 후두 레이저 수술을 시행 하기로 결정하였다. 본 술식에서 사용한 $532 \mathrm{~nm}$-pulsed KTP 레이저는 헤모글로빈에 선택적으로 흡수되어 병변의 미세순환 응고를 유발하는 레이저로, 주변 조직에 열 손상이 적다는 장 점이 있다[6,7]. 그러나 많은 양의 레이저를 병변에 사용할 경 우 열 손상으로 인한 성대 반흔(vocal fold scar)이 발생할 가
능성이 높아진다. 본 증례 환자의 경우 거대 성대 폴립을 제거 하기 위해 많은 양의 레이저 사용이 불가피하였고, 이를 예방 하기 위해 폴립 제거 후 성대 내 스테로이드 주입술을 시행하 였다. 술 후 3 개월 뒤 시행한 외래 추적관찰에서 성대 반흔없 이 회복된 소견을 보였으며, 환자는 수술에 대한 높은 만족 감을 보였다.

이에 저자는 전신마취가 불가능하여 후두미세수술을 시행 할 수 없는 DLE 환자에서 크기가 $1 \mathrm{~cm}$ 가 넘는 거대한 성대 폴립을 국소마취 하 굴곡내시경 후두 레이저 수술 방법으로 문제없이 제거하였으며, 그 과정에서 많은 양의 레이저를 조 사하였음에도 불구하고 수술 후 성대 반흔 생성없이 성공적 으로 수술을 마쳤기에 문헌고찰과 함께 보고하는 바이다.

중심 단어: 후두; 노출; 폴립; 성대; 굴곡내시경 후두 레이저 수술.

Acknowledgments

This study was supported by the Soonchunhyang University Research Fund.

Conflicts of Interest

The authors have no financial conflicts of interest.

Authors' Contribution

Conceptualization: Seung Won Lee. Data curation: You Young An. Formal analysis: You Young An, Jeong Hyun Lee. Funding acquisition: Seung Won Lee. Investigation: You Young An, Seung Won Lee. Methodology: You Young An, Seung Won Lee. Project administration: You Young An, Seung Won Lee. Resources: Ki Nam Park, Seung Won Lee. Software: You Young An, Seung Won Lee. Supervision: Ki Nam Park, Seung Won Lee. Validation: You Young An, Jeong Hyun Lee, Seung Won Lee. Visualization: all authors. Writingoriginal draft: You Young An. Writing-review \& editing: Jeong Hyun Lee, Ki Nam Park, Seung Won Lee. Approval of final manuscript: all authors.

\section{REFERENCES}

1. Ban MJ, Park JH, Ban WW, Kim JW, Park KN, Lee SW. Efficacy of fibre-optic laryngeal potassium titanyl phosphate laser surgery under local anaesthesia for the treatment of vocal polyps: A prospective study of 65 patients. Clin Otolaryngol 2018;43(6):1617-21.

2. Lee S. Fiberoptic laryngeal laser surgery. J Korean Soc Laryngol Phoniatr Logop 2018;29(2):76-8.

3. Simpson CB, Amin MR. Office-based procedures for the voice. Ear Nose Throat J 2004;83(7 Suppl 2):6-9. 
4. Hirano S, Yamashita M, Kitamura M, Takagita S. Photocoagulation of microvascular and hemorrhagic lesions of the vocal fold with the KTP laser. Ann Otol Rhinol Laryngol 2006;115(4):253-9.

5. Ohno S, Hirano S, Tateya I, Kojima T, Ito J. Management of vocal fold lesions in difficult laryngeal exposure patients in phonomicrosurgery. Auris Nasus Larynx 2011;38(3):373-80.

6. Broadhurst MS, Akst LM, Burns JA, Kobler JB, Heaton JT, Anderson
$\mathrm{RR}$, et al. Effects of $532 \mathrm{~nm}$ pulsed-KTP laser parameters on vessel ablation in the avian chorioallantoic membrane: Implications for vocal fold mucosa. Laryngoscope 2007;117(2):220-5.

7. Lechien JR, Burns JA, Akst LM. The use of 532-Nanometer-pulsed potassium-titanyl-phosphate (KTP) laser in laryngology: A systematic review of current indications, safety, and voice outcomes. Ear Nose Throat J 2021;100(1_suppl):4S-13S. 